\title{
TELEMEDICINA: \\ UN DESAFÍO PARA AMÉRICA LATINA
}

Sergio Litewka*

Resumen: La telemedicina es una tendencia creciente en la prestación de los servicios médicos. Aunque la eficacia de esta práctica no ha estado bien establecida, es probable que los países en desarrollo compartirán este nuevo paradigma con los desarrollados. Los defensores de la telemedicina en América Latina sostienen que será una herramienta útil para reducir las disparidades y mejorar la accesibilidad de atención de salud. Aunque América Latina quizá se convierta en un lugar para la investigación e investigación de estos procedimientos, no está claro cómo la telemedicina podría contribuir a mejorar la accesibilidad para las poblaciones desfavorecidas, o coexistir con sistemas de atención de salud públicos crónicamente enfermos.

Palabras clave: América Latina, Bioética, comunidades marginadas, reforma, salud, telemedicina, usuarios

\section{TELEMEDICINE: A CHALLENGE FOR LATIN AMERICA}

\begin{abstract}
Telemedicine is a growing trend in the provision of medical services. Although the effectiveness of this practice has not been well established, it is likely that developing countries will share this new paradigm with developed ones. Supporters of telemedicine in Latin America maintain that it will be a useful tool for reducing disparities and improving health care accessibility. Although Latin America might become a place for research and investigation of these procedures, it is not clear how telemedicine could contribute to improving accessibility for disadvantaged populations, or coexist with chronically ill-funded public healthcare systems.
\end{abstract}

Key words: Latin America, bioethics, marginated communities, reform, health, telemedicine, beneficiaries

\section{TELEMEDICINA: UM DESAFIO PARA AMÉRICA LATINA}

Resumo: A telemedicina é uma tendência crescente na prestação dos serviços médicos. Embora a eficácia desta prática não tenha sido ainda bem estabelecida, é provável que os países em desenvolvimento compartilharão este novo paradigma com os países desenvolvidos. Os defensores da telemedicina na América Latina sustentam que esta será uma ferramenta útil para reduzir as disparidades e melhorar a acessibilidade da atenção de saúde. Embora a América Latina, quem sabe se converta num lugar para a pesquisa e pesquisa destes procedimentos em particular, não está claro como a telemedicina poderia contribuir apara melhorar a acessibilidade para as populações desfavorecidas, o co-existir com os sistemas de atenção de saúde públicas cronicamente enfermos.

Palavras chave: América Latina, bioética, comunidades marginais, reforma, saúde, telemedicina, usuários

\footnotetext{
* Visiting Scholar, University of Miami Ethics Programs
} 


\section{Introducción}

Los avances tecnológicos están moldeando nuevos paradigmas en las relaciones entre los individuos. Estos cambios tienen una influencia directa sobre la provisión de los servicios de salud, reemplazando en muchos casos la forma tradicional en la cual se ha ejercido la medicina por la oferta de servicios médicos a distancia, en tiempo real. Estas acciones se definen, en inglés, como telemedicine, telehealth o telecare. En español, es común que se mencione el concepto de telemedicina en forma general, si bien cada uno de los términos anglosajones presenta particularidades que le son propias.

El concepto de telemedicina quedaría circunscrito a la atención médica en un ámbito institucional, mediante la interrelación de los hospitales entre sí para el desarrollo de cirugías, diagnósticos u otros procedimientos remotos.

Telehealth o telecare, en cambio, comprende el cuidado de la salud a distancia mediante la conexión entre la residencia del usuario (tanto su casa como un asilo o una cárcel) y la persona que hace el seguimiento y control de su caso.

Por lo tanto, el cuidado de la salud a distancia involucra servicios y tecnologías heterogéneas, que incluyen a las comunicaciones, las bases de datos, recursos de Internet e Intranet, transmisión y archivo de imágenes, abarcando disciplinas que exceden al concepto tradicional de la medicina, impactando sobre los individuos y las comunidades que reciben este tipo de cuidados.

Para fines prácticos, utilizaremos el termino "telemedicina", ya que es el más difundido en español, aunque dejando en claro que queremos abarcar todas las posibilidades mencionadas.
En los países centrales, el uso de la telemedicina es cada vez más frecuente, no sólo para la transmisión de imágenes (posiblemente la aplicación más difundida), sino en especialidades como neurología y neurocirugía, dermatología e, incluso, psiquiatría. Algunos autores mencionan como ventajas sobre la práctica habitual de la medicina el hecho de evitar la necesidad de desplazarse, la reducción en los costos médicos y el ahorro de tiempo (para los médicos), sosteniendo que las "videovisitas" son mucho más cortas que las consultas convencionales, evitando los saludos y despedidas de cortesía ${ }^{1}$.

En Estados Unidos, muchos de los "usuarios" son poblaciones carcelarias, integrantes de comunidades aisladas geográficamente, $\mathrm{o}$ gente que no puede deambular y no cuenta con quien les ayude a llegar a un hospital.

La generalización en el uso de la telemedicina está obligando a plantearse si realmente ofrece respuestas que sean aceptables, tanto en calidad como en eficiencia, eficacia y efectividad, ofreciendo un margen de seguridad aceptable para sus usuarios.

Tradicionalmente, la seguridad en el uso de un procedimiento o medicamento se explora mediante el desarrollo de ensayos clínicos, los que deben cumplir con parámetros internacionalmente aceptados.

No existe acuerdo sobre los criterios y parámetros que deberían establecerse, el número de casos que deberían ser incluidos y, en términos generales, cuál es el impacto sobre el bienestar y la salud de la población atendida y sobre los sistemas de salud convencionales.

1 Conford T, Dabroska EK. Ethical Perspectives in Evaluation of Telehealth. Working Papers Series (88) Department of Information Systems. London School of Economics and Political Science, July 2000. 
Quienes apoyan el uso de la telemedicina en América Latina, afirman, sosteniendo un punto de vista utilitario, que esta práctica contribuiría a una mayor equidad, al ofrecer mejor uso de los recursos disponibles a un mayor número de habitantes. Queda por verse si los problemas irresueltos de inequidades y accesibilidad a los sistemas de salud en la región pueden ser superados por la atención remota. No debería soslayarse el efecto casi hipnótico que genera una tecnología apasionante combinado con los intereses de grupos financieros y políticos locales, ávidos unos de vender y otros de figurar como responsables de cambios revolucionarios en aras del bienestar de la población.

\section{Telemedicina en América Latina}

Las implicancias éticas de este nuevo campo de la medicina aparecen al momento de establecer diferencias entre lo correcto y lo incorrecto, lo apropiado y lo inapropiado, lo bueno y lo maligno(1).

La ética, en la vertiente de la medicina, refleja una fuerte posición formal tomando principios deontológicos para valorar una acción como correcta o incorrecta, dependiendo de su conformidad con reglas morales. La ética es el reino de la razón práctica y la acción puede tener infinitas modulaciones y significados innumerables. De allí su ligazón con las consideraciones morales(2).

Hay quienes sostienen que América Latina podría beneficiarse ampliamente de las ventajas de la telemedicina(3-6) ${ }^{2}$, dado que los servicios "telemédicos" llegarían a comunidades habitualmente huérfanas de todo tipo de atención. Muchos son entusiastas y sostienen que

2 Miranda P, Medina R, Rojas R, Jugo D, et al. Grupo de Ingeniería Biomédica, Universidad de Los Andes, Facultad de Ingeniería, Mérida Red de Datos (REDULA). Sitio en Internet. Disponible en http://www.ing.ula.ve/ dmiranda/ pablo/telexp/telexp.htm la telemedicina representa un conjunto de procedimientos que impactan favorablemente en los procesos de modernización sectorial, generando oportunidades de acceso a atención médica de primer nivel a comunidades tradicionalmente marginadas.

Algunas universidades locales están desarrollando estudios para demostrar cómo pueden abordarse las complicaciones de patologías que son endémicas en determinadas zonas, la enfermedad de Chagas por ejemplo, sosteniendo que al conectar localidades desprovistas de atención médica adecuada con centros médicos especializados para la interpretación de estudios cardiovasculares podrán hacerse mejores diagnósticos Los mismos autores señalan la contracara de ese optimismo al reconocer que se carece de una red de telecomunicaciones adecuada o adaptable, en tanto ni pacientes ni médicos poseen la educación necesaria para adaptarse a su uso; tampoco queda claro de qué modo las autoridades de salud homogenizarán los criterios de regulación y control de calidad. Estos trabajos abundan en consideraciones técnicas y metodológicas aunque no parecen reflejar el mismo grado de preocupación sobre las características éticas y conceptuales de este nuevo modelo de atención.

Incluso más: sabemos que la enfermedad de Chagas es una patología invalidante generada por la coexistencia de un insecto (vector del organismo patógeno) y condiciones habitacionales y ambientales de extrema pobreza. Una vez detectada sólo puede ofrecerse tratamiento sintomático y paliativo. Sería mucho más sencillo, aunque menos impactante sin duda, actuar sobre las causas mismas de la enfermedad (mejorar las condiciones de vivienda, fumigar periódicamente, educar acerca de cómo evitar ser inoculado por el vector) en vez de invertir en costosos sistemas de comunicaciones y transmisión de datos que permitan el diagnóstico y 
seguimiento de un cuadro que una vez desarrollado es irreversible.

Este razonamiento sobre las dificultades que padece la región, obliga a interrogarse si los individuos más vulnerables no podrían llegar a ser sujetos utilizados involuntariamente para evaluar esta nueva forma de atención, más aún si se considera la cantidad de individuos vulnerables y la ausencia de normativas claras en cuanto a la protección de los sujetos de experimentación.

En todo caso, parece improbable que aquellos que pertenecen a las comunidades más marginadas puedan recibir algunas de las eventuales ventajas ofrecidas por la telemedicina. Adicionalmente a las falencias en la infraestructura de los centros de salud, hay que agregar las dificultades en la comunicación con las regiones remotas (incluso con los anillos urbanos marginales) y la escasa formación en transmisión de datos y manejo de computadoras que sufre un sector importante de los profesionales de la salud en América Latina.

\section{Telemedicina en el contexto de reforma sectorial en América Latina}

En Estados Unidos los entusiastas de la telemedicina sostienen que ésta podría disminuir sensiblemente los costos en salud. En contraste, los trabajos presentados hasta el momento para justificar el supuesto costo-efectividad están basados en datos sumamente dispersos, provenientes de contextos organizacionales y sociales diversos, planteados con una metodología tendenciosa, y reflejan evaluaciones pragmáticas más que criterios que puedan aplicarse a cualquier tipo de ensayo clínico. Por estas razones, no parece que, al presente, exista una buena evidencia de que la telemedicina sea un medio costo-efectivo para la provisión de servicios de $\operatorname{salud}(7)$.
Un documento desarrollado por la Universidad de Calgary establece una serie de condiciones que deberían ser consideradas si se fuera a integrar la telemedicina a la provisión de servicios de salud en un país determinado ${ }^{3}$. Este estudio resulta interesante si se considera el esquema centralizado y, en gran parte, dependiente del Estado que caracteriza a los sistemas de salud latinoamericanos. En ese contexto, la Universidad de Calgary sostiene que, para ser exitosa y sostenible en el tiempo, la telemedicina debe estar totalmente integrada en las estructuras y las políticas de salud. Este objetivo parece difícil de alcanzar en el estado actual de la discusión sobre el alcance de la reforma de salud en América Latina.

Durante la década del 90 gran parte de las naciones latinoamericanas emprendió diversos procesos de reforma en sus estructuras económicas y de salud. Los objetivos eran sumamente ambiciosos y pretendían lograr mayor descentralización en la red pública de servicios, mejorar la capacidad de gestión de los hospitales $\mathrm{y}$ adecuar sus fuentes y modelos de financiamiento. Con escasas excepciones, estos proyectos fracasaron debido a errores de implementación, falta de apoyo político o conflictos de interés entre distintos grupos corporativos.

Como consecuencia de esas rencillas internas, no existe casi una planificación estratégica sostenible en el tiempo, al menos en la mayor parte de los países de la región. De este modo, otro de los elementos mencionados en el documento de la Universidad de Calgary -esto es, la integración de las iniciativas de telemedicina a los planes estratégicos en salud- no parece alcanzable. Las agendas políticas en América Latina no reflejan la necesidad de fortalecer las mejoras en educa-

3 Telehealth Research Summer Institute. Socio economic policy and technical impact of telehealth. University of Calgary, Research and Training Program 2002. Documento en Internet. Disponible en http://www.fp.ucalgary.ca/ telehealth/TRSI_2002_Discussion_Document_Hebert.pdf 
ción, formación, funcionamiento administrativo, evaluación y control del sector de salud, considerando no sólo el aspecto económico, sino la calidad de los servicios prestados.

Tampoco queda claro cuáles serían los canales por los cuales interactuarían el público, los proveedores de salud y los pacientes, así como tampoco los mecanismos que regularían el ejercicio de la telemedicina, protegiendo la confidencialidad de la información recolectada, el respeto por la autonomía de los usuarios y su derecho a decidir una forma alternativa de atención.

Aunque en años venideros se siga discutiendo si el acto médico, tal como ha sido entendido por siglos, puede ser modificado al punto de evitar el contacto personal con el paciente, parece inevitable que los más vulnerables serán quienes vean aumentar su marginación al verse obligados a interactuar con su médico o enfermera a través de una pantalla y un conjunto de teclas.

Es posible que la telemedicina sea presentada como una alternativa para evitar la superpoblación de los sistemas de salud y para mejorar su accesibilidad. Esto obligará a plantearse nuevos modelos de consentimiento informado para la práctica médica a distancia, un nuevo sistema de licencias y la estandarización de la práctica de la telemedicina, incluyendo resguardos en la confidencialidad de la información trasmitida. Se deberán considerar, además, nuevos modelos retributivos, en los que se determine quién será el financista y cuáles prácticas serán aceptadas por el asegurador. Estas preocupaciones, al menos, se están discutiendo tanto en Europa como en Estados Unidos.

La Comunidad Europea ha promulgado, en 2000, una ley para reglamentar el ejercicio de la telemedicina, considerando elementos como licenciamiento de los profesionales, confidencia- lidad de la información, consentimiento informado y experimentación con sujetos humanos(8). Estados Unidos también está promulgando leyes y regulaciones tendientes a establecer estándares para la práctica de la telemedicina(9).

Finalmente, cabe preguntarse si la difusión de la telemedicina estará vinculada con una mejora en los sistemas de atención primaria y en la educación para la promoción de la salud o si, por el contrario, generará un mayor incremento en los costos médicos, agregando prácticas médicas innecesarias originadas por un incentivo a la demanda por parte de los proveedores de estos servicios.

\section{Conclusiones}

La telemedicina es una muy interesante promesa de mayor oferta en cantidad y calidad de servicios de salud. Como todo procedimiento novedoso, genera una serie de dilemas éticos. No es desdeñable el impacto sobre la relación médico-paciente basada en la filia, esto es, en un fuerte sentimiento entre las partes, definido como amistad con amor, tal como había sido descrito por los griegos.

Es cierto que resulta injusto culpar exclusivamente a la telemedicina por la muerte de esa forma especial de relación. De hecho, con anterioridad, las distintas formas de intermediación entre pacientes y médicos a través de compañías de seguros, sistemas gerenciados y seguridad social habían modificado definitivamente el escenario, y no parece probable que pueda regresarse a una época en donde el vínculo dependía exclusivamente de ellos dos. Lo que no ha cambiado y permanecerá inamovible es el principio que establece "primero, no dañar".

Si se demuestra en el futuro que la telemedicina es realmente útil para disminuir las inequidades en la provisión de servicios de salud, deberá estar integrada a una programación 
bajo criterios racionales y éticos. Este es el punto más débil que tiene América Latina. Independientemente de las deficiencias presupuestarias que padecen los gobiernos, no resulta evidente que exista voluntad de debatir los problemas y riesgos originados por la experimentación biomédica, sus riesgos y ventajas. En ese sentido, es importante considerar que esta región representa actualmente un excelente campo de experimentación, y por eso es indispensable que esta discusión comience, tanto entre los representantes políticos como entre la comunidad en general.

La globalización logrará que América Latina participe en los avances en telemedicina. Más allá de intereses contrapuestos y opiniones encontradas, este hecho es irreversible. Podría ocurrir que, en forma consistente con las crecientes disparidades de la región, la telemedicina no representara una mejora en la equidad, pero también podría suceder que un mayor número de individuos accediera a mejores opciones diagnósticas y terapéuticas, independientemente de las distancias o de los condicionantes sociales, reduciendo tiempos de espera.

Que la telemedicina sea un hecho positivo o un experimento lamentable en América Latina depende, en mucho, de los juicios y valores que prevalezcan en las discusiones de cada sociedad y del modelo de salud que esas comunidades elijan.

\section{Referencias}

1. Goodman KW. Ethics, bioethics and health informatics: An introduction. En: Goodman KW, (ed). Ethics Computing and Medicine: Informatics and the Transformation of Health Care. Cambridge: Cambridge University Press; 1998: 1-30.

2. Lolas F. Bioética y Medicina. Santiago: Editorial Biblioteca Americana; 2002.

3. Martínez A, Villarroel V, Seoane J, Del Pozo F. Analysis of information and communication needs in rural primary healthcare in developing countries. IEEE Transactions on Information Technology in Biomedicine 2005;9 (1):66-72.

4. Gómez EJ, Del Pozo F, Arredondo MT. Telemedicine: A new model of healthcare. International Journal of Healthcare Technology Management 1999;1(3-4):374-390.

5. Martínez A, Villarroel V, Seoane J, Del Pozo F. A study of a rural telemedicine system in the Amazon region of Peru. Journal of Telemedicine and Telecare 2004;10(4):219-226.

6. Vidal A. Telemedicina, una propuesta integradora. Bioingeniería y física médica cubana 2003; 4(1).

7. Whitten P, Mair F, Haycox A, May C, Williams T, Hellmich S. Systematic review of cost effectiveness studies of telemedicine interventions. British Medical Journal 2002; 324:1434-37.

8. Callens S. Telemedicine and European law. Medicine and Law 2003; 22(4):733-741.

9. Silverman RD. Current legal and ethical concerns in telemedicine and e-medicine Journal of Telemedicine and Telecare 2003;9(1):67-69. 